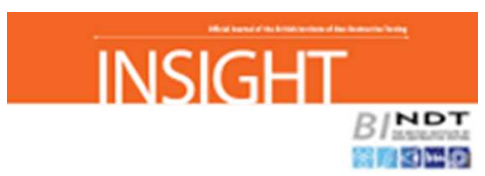

\title{
IN SITU CHARACTERISATION OF READHESION TREATMENTS FOR CEILING PAINTINGS USING UNILATERAL NMR
}

\begin{tabular}{|r|l|}
\hline Journal: & Insight \\
\hline Manuscript ID & INSI-12-2016-OA-0161.R1 \\
\hline Manuscript Type: & Original Article \\
\hline Complete List of Authors: & $\begin{array}{l}\text { Richardson, Emma; University College London, Material Studies Laboratory } \\
\text { Woolley, Elizabeth; Courtauld Institute of Art } \\
\text { Corda, Katey; Katey Corda Wall Paintings Conservation } \\
\text { Pinchin, Sarah; Historic Royal Palaces } \\
\text { Roberts, Zoe; Historic Royal Palaces }\end{array}$ \\
\hline Keyword: & Adhesives and bonding, Art, Magnetic methods, Monitoring \\
\hline
\end{tabular}

SCHOLARONE ${ }^{\text {I" }}$

Manuscripts 


\section{IN SITU CHARACTERISATION OF READHESION TREATMENTS FOR CEILING PAINTINGS USING UNILATERAL NMR}

\section{Emma Richardson ${ }^{a}$, Elizabeth Woolley ${ }^{b}$, Katey Corda ${ }^{c}$, Sophie Julien-Lees ${ }^{d}$, Sarah Pinchin ${ }^{d}$ and Zoe Roberts $^{d}$}

a Material Studies Laboratory, Department of History of Art, University College London, Gower Street, London, WC1E 6BT

b The Courtauld Institute of Art, The Strand, London, WC2R ORN

c Katey Corda Wall Paintings Conservation, London

d Historic Royal Palaces, Hampton Court Palace, Surrey, KT8 9AU

\section{ABSTRACT}

Ceiling and wall paintings pose significant challenges for historic house management due to their position at the interface between the environment and building. Tight restrictions to modifications on built heritage prevent total control of the environment, resulting in temperature and humidity fluctuations. Different hygrothermal responses within the wall painting stratigraphy frequently lead to fracturing and lifting of paint layers, necessitating remedial conservation to readhere areas of detachment. Assessing the success of readhesion interventions is difficult due to the hidden nature of the treatment and, often, limited access.

In this paper, we present comparative results of two different adhesive treatments employed during the conservation of the baroque ceiling painting in the Queen's Staircase at Hampton Court Palace, analysed with unilateral nuclear magnetic resonance. This non-invasive technique enabled monitoring of the adhesive systems - based on Jun Funori and BEVA ${ }^{\circledast} 371$ - up to a depth of 3,500 um into the ceiling by providing specially resolved proton density profiles before and after treatment. Results offer a unique and pertinent assessment of treatment areas within a strictly limited timeframe. It is shown that the solvent carrier leaves the system within 24 hours, and that the ultimate deposition of the adhesive can be identified. 


\section{INTRODUCTION}

Loss of adhesion is a common wall painting conservation problem [1]. Its remediation is complicated due to the paint layers forming the interface between the environment and the building. As such, they are especially sensitive to water vapour effects such as hygroscopic absorption and condensation. The presence of salts, uncontrollable environmental conditions, and compatibility of original and previously added materials may all circumscribe wall painting interventions [2].

Deposition of the adhesive (distinct from the carrier) is a critical aspect of the intervention and notoriously hard to assess as it is essentially a blind treatment [3].

The Queen's Staircase ceiling at Hampton Court Palace (Figure 1), painted by William Kent in 1734, constitutes approximately $140 \mathrm{~m}^{2}$ of oil paint on lime-hair plaster. In 2001, an inspection of the ceiling painting revealed widespread flaking across the entire surface. The deterioration observed takes the form of delamination of the paint layers from the plaster substrate (Figure 2). The first attempt to fix the flaking with a conventional wall paintings adhesive, Plextol B500 in deionised water, rapidly failed. This prompted an intensive period of investigation and documentation.

The detail of these investigations has been recounted elsewhere [4] and is summarised here. The point of original failure was established to be in the ground layer, between the oil paint and the support (Figure 3), possibly as a result of poor preparation [5]. The cause was hypothesised to be an environmental response to original technique and/or physical history i.e. water infiltration from the apartments above [6]. Extensive investigations into environmental controls resulted some retrofitting to better buffer the building [7] . A programme of emergency flake fixing has been used to minimise the impact of losses to the painted scheme, during which trials assessing different adhesives continued, with BEVA ${ }^{\circledR} 371$ identified as the most satisfactory adhesive [8]. Annual spot inspections take place from a cherry picker lift and in 2010 , comprehensive quinquennial condition monitoring from a boarded out bird cage scaffolding began. 
A detailed condition check and emergency fixing campaign was undertaken in February 2016 by a new team of conservators. This afforded the opportunity for non-invasive, in-situ assessment of readhesion treatments using unilateral nuclear magnetic resonance (NMR) with the aim of visualising the deposition and drying time of two adhesives. Access to the ceiling painting was time limited, and necessitated working from a scaffolding, which complicated analysis. Nevertheless, insights from in-situ analysis of the real object were gained which would not have been possible from laboratory mock-ups.

Unilateral nuclear magnetic resonance relaxometry offers the potential to understand the stratigraphy of paintings and to monitor the diffusion of conservation treatments, namely the migration of solvent and deposition of adhesives within the substrate. Portable NMR provides hydrogen spin-lattice and spin-spin relaxation times ( $T_{1}$ and $T_{2 \text { eff }}$ respectively), relying on magnetization from a single-sided permanent magnet inducing a gradient external to the device. At depths approximating 5,000 um (ca. $5 \mathrm{~mm}$ ) is a uniform lateral analysis volume, with a depth resolution achievable in the region of $50 \mathrm{um}$, dependant on the acquisition parameters and radio frequency (rf) pulse length.

This non-invasive analytical technique has already shown great potential within the field of conservation and heritage science. Applications have included monitoring capillary action of moisture through wall paintings [9], the characterisation of oil stains on paper [10], and non-invasive depth profiling of easel paintings to determine the stratigraphy of paint and primer layers [11-13]. However, the most extensive applications of unilateral NMR within cultural heritage have been the study of solvent diffusion and mobility, where it has been successfully employed to monitor conservation cleaning treatments on painted surfaces $[5,10,14-16]$.

In the work presented here, unilateral NMR was employed to interrogate the depth penetration and final deposition of adhesive used during the conservation of the Queen's Staircase ceiling painting. The device was positioned such that the excitation cross section was parallel to the surface of the 
ceiling. Two adhesives were compared; $\mathrm{BEVA}^{\circledR} 371$, as the established adhesive used during emergency fixing campaigns [17] and Jun Funori, not previously trialled at this site.

BEVA $^{\circledast} 371$ is a heat-activated adhesive based on ethylene vinyl acetate copolymer in paraffin wax, and areas previously treated with this adhesive were observed to be hydrophobic in 2016 (Figure 2). Additionally, many solvents suitable for $\mathrm{BEVA}^{\circledR} 371$ also solubilised previously applied varnishes and repainting. These two factors have implications for retreatability, so an alternative adhesive was sought.

Jun Funori is a purified polysaccharide extracted from the red algae genus Gloiopeltis [18]. It is favoured in conservation interventions due to its low surface tension, matte finish, solubility in water, and nontoxic properties [19] . It is also thermo-hygrally stable, optically stable, and not particularly susceptible to biological attack [1]. It was selected for trialling for four reasons:

1) it forms a relatively weak bond [20], allowing failure at the original fracture if re-exposed to stress

2) it forms a viscous solution at very low concentrations, reducing the amount of material added to the system and therefore limiting alterations in porosity and thermal-hygral behaviour of original material

3) the water carrier is highly polar and therefore does not disrupt previously applied resin coatings

4) it does not curtail retreatment, a key ethical consideration when designing a conservation intervention.

Previous conservators had avoided water-based adhesives, lest the treatment cause swelling of the unbound chalk layer and exacerbate instability. Although aqueous solutions do have the potential to cause swelling and localised fluctuations in humidity, the absolute amount of water introduced to the painting system is small and was posited to evaporate swiftly. Evaporation time and movement 
of water within the paint layers were aspects to be investigated with NMR, in order to confirm Jun Funori as a suitable adhesive.

Recent research [1] indicates high concentrations of some soluble salts may increase gelling and so hinder penetration of the funori into the substrate, although this did not discount its use in this case. Firstly, no efflorescence was noted on the painting, despite temperature and relative humidity fluctuation, indicating no obvious salt contamination. Secondly, the goal of this intervention was to readhere two coherent layers, rather than consolidate decohering material; in fact, potential film forming might be considered beneficial in this case.

\section{EXPERIMENTAL}

\section{ADHESIVE PREPARATION AND APPLICATION}

\section{JUN FUNORI}

A $1 \%$ Jun Funori solution was prepared in water containing $2 \%$ isopropanol. Prior to injection the adhesive was warmed and the treatment area was pre-wetted with a 1:1 water/isopropanol solution to reduce surface tension and encourage capillary action of the adhesive into the pores of the paint and substrate. A warm spatula was used to help flakes to relax back into position and to encourage evaporation of the carrier. Excess adhesive was cleared using a barely damp swab.

$B E V A^{\circledR} 371$

A 1:4 weight/volume BEVA ${ }^{\circledR} 371$ in petroleum spirits was prepared by gently heating to encourage dissolution. Once in solution the BEVA ${ }^{\circledast} 371$ was injected behind the paint flake (Figure 4) and a few minutes allowed for solvent evaporation before heat activation using a warm spatula; BEVA ${ }^{\circledR} 371$ has a heat activation temperature of $65^{\circ} \mathrm{C}$ and petroleum spirits an evaporation temperature of between $60-80^{\circ} \mathrm{C}$. Warmth also helped the flake soften and relax back into position. Excess adhesive was cleared from the area using petroleum spirits on swabs. 
IN SITU NMR INSTRUMENTAL SETUP

The unilateral NMR analysis was undertaken from the birdcage scaffolding installed in the Queen's Staircase, permitting depth profiles of the ceiling painting. The NMR instrument was mounted onto a precision lift on a tripod. The sampling depth of the instrument is limited to $5,250 \mu \mathrm{m}$, therefore optimum depth profiles would require the magnet to be directly in contact with the surface of the ceiling painting. However, due to the fragility of the paint surface of the ceiling a layer of expanded foam was placed between the instrument and the painting, thus reducing the maximum depth of sampling into the ceiling. The thickness of compressed foam ranged between 1,500-2,000 $\mu \mathrm{m}$, reducing maximum sampling depths to $3,750-3,250 \mu \mathrm{m}$. Initial positioning of the magnet's $\mathrm{rf}$ coil parallel to the surface of the painting was achieved by increasing the height of the tripod using three secured scissor jacks. Once in place, all subsequent fine movement of the magnet was controlled via the precision lift connected to a computer.

Owing to the presence of the magnet, before analysis could start we needed to establish that there were no metal fixings behind the ceiling painting to a) prevent the magnet attracting metal fixtures and b) prevent interference with the magnetization signal [21]. Therefore, before the two regions for treatment and analysis could be identified it was necessary to consult Hampton Court Palace architectural drawings to determine the presence of modern structural reinforcements, such as rolled steel joists (RSJ) positioned above the ceiling. The positions of the joists were subsequently confirmed using a thermal camera and verified through examination of the void above the ceiling painting accessed from the room above. Figure 5 illustrates the positioning of the RSJs behind the painting and the two regions selected for conservation and analysis.

\section{NMR PARAMETERS AND DATA PROCESSING}

Unilateral NMR relaxation studies were carried out in situ using a PM-5 Profile ${ }^{1} \mathrm{H}$ NMR MOUSE (Magritek, Aachen, Germany), with a field strength of approximately $0.5 \mathrm{~T}$ and $19 \mathrm{MHz}$ proton 
frequency, coupled with a Kea2 spectrometer (Magritek). A precision lift enabled vertical positioning of the magnet relative to the ceiling's paint surface, positioned such that the homogenous excitation volume was within the painting. The lateral sampling area was $13 \times 13 \mathrm{~mm}^{2}$ with a maximum sampling depth of $5,250 \mu \mathrm{m}$. For each excitation slice the decay of the traverse magnetization was recorded by a Carr-Purcell-Meiboom-Gill (CPMG) echo radiofrequency pulse sequence [22, 23], used to obtain spin echoes at different depths through the substrate. This enabled effective spin-spin relaxation times ( $\left.T_{2 \text { eff }}\right)$ to be calculated from the CPMG echo train at each depth [14].

The instrument was used in 'Profile' mode, which applies CPMG pulse sequences at specified depths through the painting structure [24]. The analytical volume was moved at increments of $50 \mu \mathrm{m}$ over the total depth of $5,240 \mu \mathrm{m}$ with pulse sequence parameters for each adhesive treatment as presented in Table 1. Data were acquired using Prospa software (Magritek, Aachen, Germany) and processed using OriginPro 2015 Software. 2D contour maps of recorded CPMG decays are presented for each Profile scan obtained before the ceiling was treated, after treatment and during the drying process. The $x$-axis represents the CPMG echo decay and the $y$-axis representing depth of sampling in microns. Additionally, by plotting the sum of the signal amplitude of the $1^{\text {st }}$ through $2^{\text {nd }}$ echoes against depth the location of the paint layers and deposition of the adhesive can be graphically represented. The sum of the signal amplitude was smoothed using Savitzky-Golay filtering with a five point window and quadratic polynomial fit.

\section{RESULTS AND DISCUSSION}

JUN FUNORI TREATMENT: TEST POSITION 1

\section{BEFORE TREATMENT}

A depth profile scan was carried out at Position 1 before treatment with Jun Funori. The magnet was brought to the top of the precision lift, positioning the excitation volume as far into the paint 
structure as possible, and the lift programmed to move downwards by $50 \mu \mathrm{m}$ moving the excitation volume through the ceiling towards the front of the painting. At each $50 \mu \mathrm{m}$ cross section a CPMG echo relaxation decay was acquired, plotted in Figure 6a as a 2D contour map showing CPMG echo decay against depth of measurement. Although weak, an initial signal is seen to occur at 2,150 $\mu \mathrm{m}$, equating to a total sampling depth of $3,100 \mu \mathrm{m}$ into the ceiling at Position 1 . From 2,100-0 $\mu \mathrm{m}$ the excitation volume of the instrument is outside of the paint structure i.e. sampling air, which accounts for the low background signal.

The strongest signal is detected at 2,350 $\mu \mathrm{m}, 200 \mu \mathrm{m}$ into the ceiling painting, which is likely to originate from the oil-based paint layers. The paint layers are expected to have the highest proton density in what is essentially otherwise an inorganic structure. Depth 2,350 $\mu \mathrm{m}$ was interrogated more fully by locating the excitation volume of the NMR at this depth to acquire an improved CPMG echo decay (Figure 6c). The echo decay was acquired with an increased number of scans (256) to improve signal to noise and enable the relaxation time to be determined by curve fitting. Figure $6 c$ shows the CPMG echo decay with the excitation volume centred within the paint layer. Fitting a single exponential to the data gives a $T_{2 e f f}$ relaxation time of $0.09 \mathrm{~ms} \pm 0.02$. This relatively quick relaxation corresponds to similar findings of Fife et al [16] ascribed to the behaviour of a hardened, crosslinked organic oil binder. Drying oils undergo oxidation and polymerization reactions, which in turn reduces free volume and limits decoherence in the magnetization.

The weaker signal between $2,200-2,150 \mu \mathrm{m}$ is thought to originate from the presence of a varnish layer. Cross sectional microscopy of a paint flake acquired elsewhere from the ceiling painting suggests an outer, optically transparent layer measuring in the region of $100 \mu \mathrm{m}$ (Figure 3) Although not a direct comparison to the location analysed in Position 1 , cross sections from the paintings have identified a variable palette and in some cases a varnish layer. 
POST TREATMENT ADHESIVE AND SOLVENT INGRESS

The NMR was lowered on the precision lift to enable the Jun Funori adhesive to be injected behind the paint flake and ironed back into place. Once the treatment had been carried out the instrument was brought back into contact with the ceiling and a series of ten consecutive profiles were acquired to monitor the depth of penetration of the treatment and movement of the solvent (water) front.

Figure 7a shows the 2D contour map for the first of ten profile scans, directly following treatment with the Jun Funori adhesive in water. The first profile scan was acquired approximately 30 minutes after the initial adhesive injection. It is apparent that the signal in the region of the paint layer has increased fivefold, in line with an increase in the proton density. The most intense signal is also detected across three sampling steps after treatment, $2,350-2,250 \mu \mathrm{m}$, compared to one sampling step for the untreated paint layer; the former equating to a depth of approximately $150 \mu \mathrm{m}$ and the latter $50 \mu \mathrm{m}$.

It was not possible to acquire an optimised CPMG echo decay from 2,350-2,250 $\mu \mathrm{m}$ due to the dynamic nature of this particular experiment i.e. running ten consecutive profiles scans to capture solvent movement. However, fitting a single exponential decay to the CPMG echo decay acquired at $2,350 \mu \mathrm{m}$ during the profile scan suggests a $\mathrm{T}_{2 \text { eff }}$ relaxation time in the region of $0.17 \mathrm{~ms} \pm 0.04$

(Figure 7c). This increase in relaxation time reflects the increased mobility and decoherence of the protons in the solvent/adhesive solution.

The average echo amplitude of the $16^{\text {th }}$ through $32^{\text {nd }}$ echo is plotted in Figure $7 \mathrm{~b}$ (dashed line). It is show that there is a low intensity, broad signal across the $2,250-2,400 \mu \mathrm{m}$ region that indicates that the adhesive layer has not fully relaxed by the end of the CPMG sequence. This is a reflection of the mobility of the protons in the adhesive/solvent solution, increasing the time required for complete relaxation and realignment with the magnetic gradient.

The $2 \mathrm{D}$ contour map in Figure 8 shows the sum of the echo amplitude for the $1^{\text {st }}$ through $2^{\text {nd }}$ echo at each sampling depth over ten consecutive profile scans. The signal appears to have dispersed across 
$1,950-2,450 \mu \mathrm{m}$ by profile scan five, suggesting that the solvent has diffused inside the ceiling painting and to the region immediately in front of the painted surface. Later consecutive scans appear to confirm this as the total proton density originates from the ceiling/air interface rather than into the bulk substrate. The solvent does not move into the plaster layers during drying as no significant increase in signal can be seen in the bulk. This has important implications for the use of water based adhesives in such composite structures. These results indicate that evaporation of the solvent tends towards the front of the ceiling painting, which reduces the possibility of damage to the bulk structure caused by moisture sorption. We are undertaking further work to confirm this interpretation.

\section{TWENTY FOUR HOURS AFTER TREATMENT}

The 2D contour map in Figure 9a shows the depth resolved CPMG echo decays acquired 24 hours after the initial injection of the Jun Funori adhesive. It is apparent there is a significant drop in the proton density 24 hours after treatment. The decrease in signal suggests that the solvent has fully evaporated, further supported by the loss of signal in the average echo amplitude of the $16^{\text {th }}$ through $32^{\text {nd }}$ echoes in Figure $9 \mathrm{~b}$ (dashed line).

Although much reduced after 24 hours, the signal is twice that of the proton density detected prior to treatment and this increase is attributed to the deposit of the adhesive (Figure $6 b$ and Figure 9b). It is apparent from the 2D contour map that the signal spans a larger depth than before adhesive injection; the signal originating from a $50 \mu \mathrm{m}$ cross section before treatment and a depth of approximately $250 \mu \mathrm{m}$ after treatment (Figure 9a). Fitting an exponential to the CPMG echo decay at 2,350 $\mu \mathrm{m}$ (Figure 9c) the dry adhesive is shown to have a quicker relaxation time than that of the adhesive dissolved in the solvent carrier; the $T_{2 \text { eff }}$ relaxation time is $0.08 \mathrm{~ms} \pm 0.02$ compared to 0.17 $\mathrm{ms} \pm 0.04$. 
BEVA $^{\circledR} 371$ TREATMENT: TEST POSITION 2

\section{BEFORE TREATMENT}

Prior to treatment with BEVA $^{\circledR} 371$ a depth profile scan was carried out in Position 2, acquiring a CPMG echo decay at $50 \mu \mathrm{m}$ steps and plotted in Figure 10a as a 2D contour map. It is apparent that the signal covers a larger depth than the region analysed prior to Jun Funori injection. This is likely due to the fact that the paint flake had lifted away from the plaster and is no longer parallel to the ceiling, therefore covered a greater signal depth. This is supported by the sum of the echo amplitude of the $1^{\text {st }}$ through $2^{\text {nd }}$ echo at each depth shown in Figure $10 \mathrm{~b}$. This plot shows that the proton signal spans from $1,750-2,700 \mu \mathrm{m}$, a depth of $950 \mu \mathrm{m}$. This broad signal appears to indicate that the void measures in the region of $950 \mu \mathrm{m}$, which fits well with visual observation.

\section{POST TREATMENT ADHESIVE AND SOLVENT INGRESS}

The precision lift was lowered to allow access for treatment. Following injection of the BEVA ${ }^{\circledR} 371$ the adhesive was heat treated using a flat iron to activate the adhesive and to encourage the paint flake to return to its original position, flush with the ceiling. Excess material was then swabbed from the surface with petroleum spirits.

The 2D contour map in Figure 11a and echo amplitude plot Figure $11 \mathrm{~b}$ shows an increased background signal across the entire analysis depth, with the greatest signal increase apparent at the front of the ceiling where the adhesive was injected behind the paint layer. Although the signal spans the entire sampling depth, there are three primary regions of interest, namely $2,400 \mu \mathrm{m}$, 2,100-1,750 $\mu \mathrm{m}$ and $1,750-1,550 \mu \mathrm{m}$.

The signal at 2,400 $\mu \mathrm{m}$ is believed to originate from the adjacent area of non-flaking paint i.e. paint from the stable regions surrounding the delaminated paint flake. Spanning just over $50 \mu \mathrm{m}$ in depth and exhibiting a strong signal, it seems likely that this signal sitting further back within the depth of 
sampling originates from the stable structure. This signal is also seen at the same depth prior to treatment (Figure 10b).

Directly in front of this region spanning $2,100-1,750 \mu \mathrm{m}$ is another strong, broad signal, which is assigned to the bulk adhesive and delaminated paint layer. The signal originating from this region has increased by a third following treatment and the corresponding CPMG echo decay shows an increase in $T_{2 \text { eff }}$ relaxation from $0.06 \mathrm{~ms} \pm 0.02$ to $0.08 \mathrm{~ms} \pm 0.04$. The exponential decays are fitted to data derived from the profile scans, which were optimised for time, rather than fitted to individual CPMG data optimised to improve signal to noise. Therefore it should be noted that these $T_{2 \text { eff }}$ values are tentative, exhibiting high errors and values close to that of a single echo time $(0.05 \mathrm{~ms})$.

There is a weaker more defined signal across the region of $1,750-1,550 \mu \mathrm{m}$ at the outmost surface of the ceiling, possibly due to the presence of a varnish layer. A signal of the same intensity is seen before injection of the adhesive, although after treatment appears to have moved forwards by approximately $100 \mu \mathrm{m}$ relative to the signal at $2,400 \mu \mathrm{m}$. This suggests that the adhesive has prevented full alignment of the paint flake back into the recess and that the paint flake standing proud of the surrounding paint work. The total depth of the signal before and after treatment with $\mathrm{BEVA}^{\circledast} 371$ also supports this interpretation and is likely due to the deformed flake not fully flattening back into place with heat. However, on visual inspection the conservation treatment did appear to have significantly reduced the void. Perhaps readhesion is via anchoring of a few discrete points, rather re-bonding of the complete flake area.

After treatment with BEVA ${ }^{\circledR} 371$ there is an apparent increase in the background signal throughout the depth of the matrix (Figure 10a and 11a). The analysis was undertaken within 30 minutes of injecting the adhesive/solvent mixture and this increase in signal is thought to be due to solvent migration through the substrate. The solvent carrier used was a relatively volatile petroleum spirit, with a boiling point in the region of $60-80^{\circ} \mathrm{C}[25]$, that appears to have diffused through the sampling depth. Unfortunately, due to time constraints on the scaffolding it was not possible to 
reanalyse the same area 24 hours after treatment to confirm whether this increase in signal was persistence and was in fact due to evaporating solvent.

\section{CONCLUSIONS}

Non-invasive, non-destructive analysis of the paint structure and consolidation treatments was made possible using a unilateral NMR in situ mounted on a precision lift. Custom-made scissor jacks enabled the instrument to be carefully positioned, ensuring that that the excitation cross section was horizontal with the layered paint structure. There were limitations in the precision of analysis owing to vibration in the scaffold, exhibited as small shifts in the signal when personnel mounted the scaffold, or after repositioning of the NMR magnet between treatments.

The NMR profile analysis indicated a signal from the paint layer in the region of $50 \mu \mathrm{m}$ thick. After treatment with Jun Funori, Position 1 exhibited a signal spanning a greater depth suggesting penetration of the adhesive up to $250 \mu \mathrm{m}$. The analysis undertaken 24 hours after treatment clearly showed that the adhesive had dried, seen as a shorter relaxation time, demonstrating the water component had been lost from the matrix. The profile scan of the sum of the echo amplitude of the $1^{\text {st }}$ through $2^{\text {nd }}$ echoes over the duration of the initial drying process also suggests that the waterfront moves towards the front of the painting rather than into the bulk of the substrate.

The large void caused by delamination of the paint layer at Position 2 was seen as a broad signal in the 2D contour map. After treatment with BEVA ${ }^{\circledR} 371$ the adhesive appeared to cover a depth of 350 $\mu \mathrm{m}$, suggesting that the flake was still not perfectly aligned after treatment. The 2D contour map showed an increased signal throughout the depth of the substrate after treatment with BEVA ${ }^{\circledR} 371$ attributed to diffusion of the volatile petroleum spirit solvent.

Although time and access allowed only one area for each adhesive to be analysed, results seem to confirm that the adhesive is deposited in a layer between paint and substrate, necessary for good re- 
adhesion. This encouraging data can be reviewed over the longer-term as the adhesives' performances are evaluated visually during the annual inspection schedule of the ceiling. Through the application of in-situ analysis to interrogate interactions between conservation treatments and the stratigraphy of paintings, we ultimately hope to better understand patterns of deterioration and how to remediate them.

\section{ACKNOWLEDGMENTS}

We would like to thank Kate Frame, Head of Conservation and Collection Care, Historic Royal Palaces. We are grateful to the conservation site team, in particular Dan Cull and Aimee Simms for arranging logistics for the onsite analysis and for their flexibility, and Sophie Stewart, for accommodating the analysis into the work schedule. We also thank Professor Sharon Cather, The Courtauld Institute of Art, for the loan of their infrared thermography camera to locate the internal RSJ's. Thanks are also given to Cougar Developments Ltd for designing and manufacturing the scissor jack lift.

\section{REFERENCES}

1. Catenazzi, K., Evaluation of the use of Funori for consolidation of powdering paint layers in wall paintings. Studies in Conservation, 2016. March (29): p. 1-8.

2. Cather, S., Assessing Causes and Mechanisms of Detrimental Change to Wall Paintings, in Conserving the Painted Past: Developing Approaches to Wall Painting Conservation, R. Gowing and A. Heritage, Editors. 2003, Earthscan.

3. Soppa, K., T. Laaser, and C. Krekel. Visualizing the Penetration of Adhesives using Fluorescent Labelling in Adhésives and Consolidants for Conservation, Research and Application. 2011. Ottawa: Canadian Conservation Institute. 
4. Roberts, Z. and J. Burbidge, Coming unstuck! The approach to the treatment of a recurrently flaking Baroque ceiling painting, in Adhesives and consolidants in painting conservation, A. Barros D'Sa, Editor. 2012, Archetype Publications: London.

5. Davies, J., William Kent Ceiling Paintings Kensington Palace and Hampton Court Palace. 2010, Jane Davies Conservation. Unpublished.

6. Burbidge, J., Queen's Staircase: Treatment of the Painted Ceiling. 2003, Hampton Court Palace: Unpublished.

7. Roberts, Z., et al. Reconciling environmental stability with open access: The case study of the Queen's Stairs, Hampton Court Palace. in ICOM-CC 17th Triennial Conference Preprints. 2014. Melbourne: International Council of Museums.

8. Woolley, E. and K. Corda, Condition Survey and Emergency Fixing at the Queen's Staircase, Hampton Court Palace. 2016, Hampton Court Palace: Unpublished

9. Di Tullio, V., et al., Unilateral NMR: A Noninvasive Tool for Monitoring In Situ the Effectiveness of Intervention to Reduce the Capillary Raise of Water in an Ancient Deteriorated Wall Painting. International Journal of Spectroscopy, 2012. 2012: p. 10.

10. Del Federico, E., et al., Unilateral NMR applied to the conservation of works of art. Analytical and Bioanalytical Chemistry, 2010. 396(1): p. 213-220.

11. Blümich, B., et al., Noninvasive Testing of Art and Cultural Heritage by Mobile NMR. Accounts of Chemical Research, 2010. 43(6): p. 761-770.

12. Anselmi, C., et al., The study of cyclododecane as a temporary coating for marble by NMR profilometry and FTIR reflectance spectroscopies. Applied Physics A, 2011. 104(1): p. 401406.

13. Capitani, D., V. DiTullio, and E. Caponetti, Nuclear Magnetic Resonance to characterize and monitor Cultural Heritage. Progress in Nuclear Magnetic Resonance Spectroscopy, 2013. 64:

p. 29-69. 
14. Angelova, L.V., B. Ormsby, and E. Richardson, Diffusion of water from a range of conservation treatment gels into paint films studied by unilateral NMR: Part I: Acrylic emulsion paint. Microchemical Journal, 2016. 124: p. 311-320.

15. Chiantore, O., D. Scalarone, and T. Learner, Characterization of Artists' Acrylic Emulsion Paints. International Journal of Polymer Analysis and Characterization, 2003. 8(1): p. 67-82.

16. Fife, G.R., et al., Characterization of aging and solvent treatments of painted surfaces using single-sided NMR. Magnetic Resonance in Chemistry, 2015. 53(1): p. 58-63.

17. Burbidge, J., Queen's Staircase: Painted Ceiling Survey. 2010, Hamton Court Palace: Unpublished.

18. Geiger, T. and F. Michel, Studies on the Polysaccharide Jun Funori Used to Consolidate Matt Paint. Studies in Conservation, 2005. 50(3): p. 193-204.

19. Swider, J.R. and M. Smith, Funori: Overview of a 300-year-old Consolidant. Journal of the American Institute for Conservation, 2005. 44(2): p. 117-126.

20. Michel, F. Funori and Jun Funori: Two Related Consolidants With Surprising Properties. in Adhésives and Consolidants for Conservation, Research and Application. 2011. Ottawa: Canadian Conservation Institute.

21. Alfeld, M. and J.A.C. Broekaert, Mobile depth profiling and sub-surface imaging techniques for historical paintings -A review. Spectrochimica Acta Part B: Atomic Spectroscopy, 2013. 88: p. 211-230.

22. Carr, H.Y. and E.M. Purcell, Effects of Diffusion on Free Precession in Nuclear Magnetic Resonance Experiments. Physical Review, 1954. 94(3): p. 630-638.

23. Meiboom, S. and D. Gill, Modified Spin-Echo Method for Measuring Nuclear Relaxation Times. Review of Scientific Instruments, 1958. 29(8): p. 688-691.

24. Perlo, J., F. Casanova, and B. Blümich, Profiles with microscopic resolution by single-sided NMR. Journal of Magnetic Resonance, 2005. 176(1): p. 64-70.

25. Petroleum Ether, in MSDS. 2003, EMD Chemicals: New Jersey. 


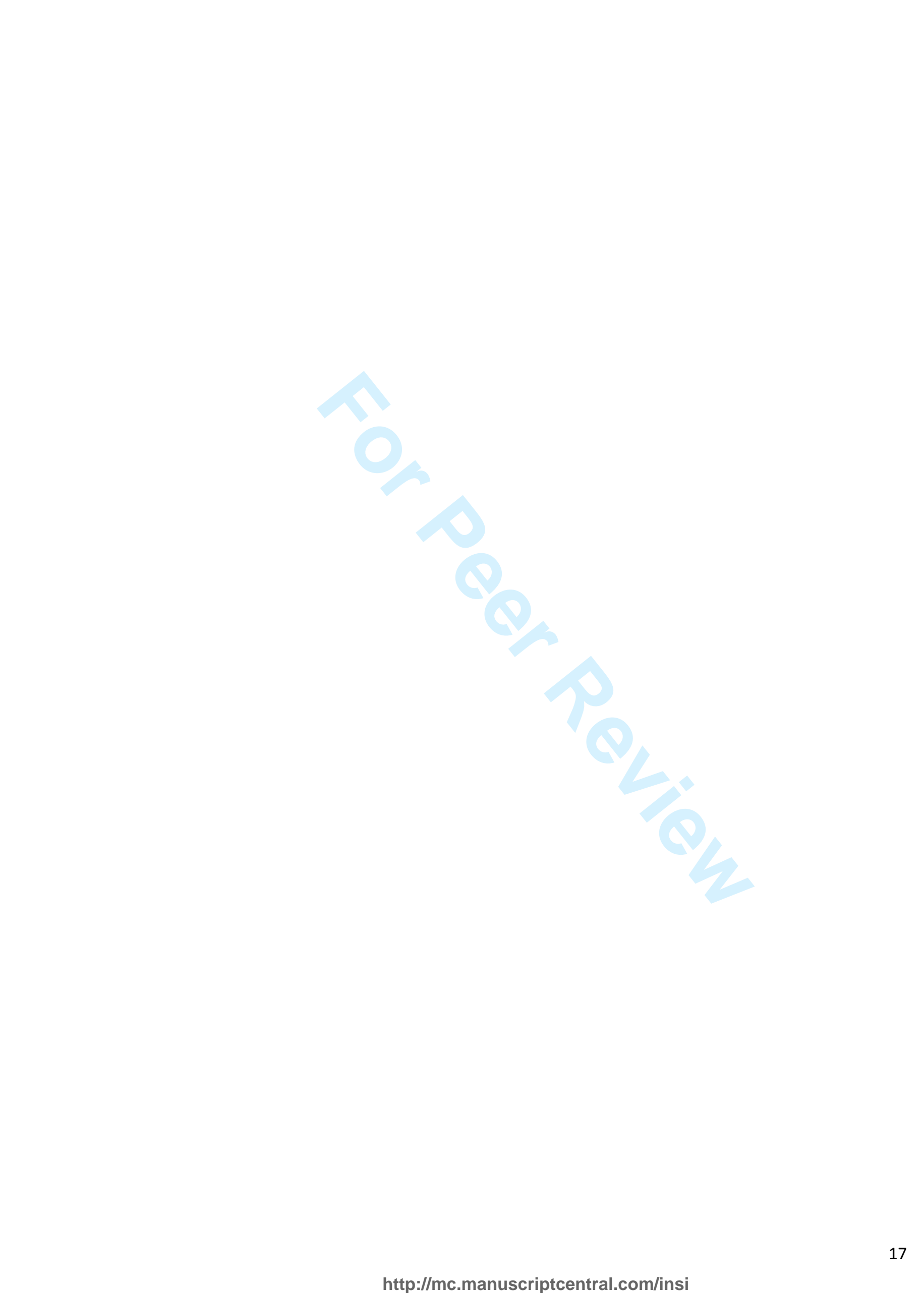




\begin{tabular}{lccccccc}
\hline Adhesive & Position & $\begin{array}{c}\text { Repetition } \\
\text { Time } \\
(\mathrm{ms})\end{array}$ & $\begin{array}{c}\text { No. } \\
\text { Scans }\end{array}$ & $\begin{array}{c}\text { No. } \\
\text { Echoes }\end{array}$ & $\begin{array}{c}\text { Echo } \\
\text { Time } \\
(\mu \mathrm{m})\end{array}$ & $\begin{array}{c}\text { Pulse } \\
\text { Length } \\
(\mu \mathrm{s})\end{array}$ & $\begin{array}{c}\text { Step Size } \\
(\mu \mathrm{m})\end{array}$ \\
\hline $\begin{array}{c}\text { Jun Funori in } \\
\text { Water }\end{array}$ & Position 1 & 300 & 32 & 32 & 54 & 6.75 & 50 \\
$\begin{array}{c}\text { BEVA } \\
\text { Petroleum } 371 \text { in }\end{array}$ & Position 2 & 150 & 256 & 32 & 54 & 6.75 & 50 \\
$\quad$ Spirit & & & & & & &
\end{tabular}




\section{FIGURE CAPTIONS}

Figure 1 The Queen's Staircase at Hampton Court Palace. CHistoric Royal Palaces. Photo: Nick Guttridge

Figure 2 Delamination of paint layers from the plaster substrate and water droplets on hydrophobic $\mathrm{BEVA}^{\circledR} 371$ adhesive from previous treatment

Figure 3 Cross section from William Kent ceiling painting, painted 1734, The Queen's Staircase. Magnification 200x

Figure 4 Injection of BEVA ${ }^{\oplus} 371$ adhesive solution behind paint flake

Figure 5 Image of The Queen's Staircase ceiling painting by combined rectified photographs showing locations of NMR analysis and rolled steel joists behind the painting. (CHistoric Royal Palaces

Figure 6 Relaxation data acquired from Position 1 prior to treatment with Jun Funori adhesive (a) 2D contour map showing CPMG echo decays through the depth of the ceiling at $50 \mu \mathrm{m}$ steps, (b) sum echo amplitude of the $1^{\text {st }}$ through $2^{\text {nd }}$ echoes at each sampling depth at $50 \mu \mathrm{m}$ steps and (c) CPMG echo decay at a depth of $2350 \mu \mathrm{m}$

Figure 7 Relaxation data acquired from Position 130 minutes after treatment with Jun Funori adhesive (a) 2D contour map showing CPMG echo decays through the depth of the ceiling at $50 \mu \mathrm{m}$ steps, (b) sum echo amplitude of the $1^{\text {st }}$ through $2^{\text {nd }}$ echoes at each sampling depth at $50 \mu \mathrm{m}$ steps and (c) CPMG echo decay at a depth of $2350 \mu \mathrm{m}$

Figure $82 \mathrm{D}$ contour map of the sum echo amplitude for the $1^{\text {st }}$ through $2^{\text {nd }}$ echoes at each sampling depth over ten consecutive profile scans showing movement of the proton density signal towards the front of the ceiling painting 
Figure 9 Relaxation data acquired from Position 124 hours after treatment with Jun Funori adhesive (a) 2D contour map showing CPMG echo decays through the depth of the ceiling at $50 \mu \mathrm{m}$ steps, (b) sum echo amplitude of the $1^{\text {st }}$ through $2^{\text {nd }}$ echoes at each sampling depth at $50 \mu \mathrm{m}$ steps and (c) CPMG echo decay at a depth of $2350 \mu \mathrm{m}$

Figure 10 Relaxation data acquired from Position 2 prior to treatment with BEVA ${ }^{\circledR} 371$ adhesive (a) 2D contour map showing CPMG echo decays through the depth of the ceiling at $50 \mu \mathrm{m}$ steps, (b) sum echo amplitude of the $1^{\text {st }}$ through $2^{\text {nd }}$ echoes at each sampling depth at $50 \mu \mathrm{m}$ steps and (c) CPMG echo decay at a depth of $1950 \mu \mathrm{m}$

Figure 11 Relaxation data acquired from Position 230 minutes after treatment with BEVA ${ }^{\circledR} 371$ adhesive (a) 2D contour map showing CPMG echo decays through the depth of the ceiling at $50 \mu \mathrm{m}$ steps, (b) sum echo amplitude of the $1^{\text {st }}$ through $2^{\text {nd }}$ echoes at each sampling depth at $50 \mu \mathrm{m}$ steps and (c) CPMG echo decay at a depth of $1950 \mu \mathrm{m}$

\section{TABLE CAPTION}

Table 1 Experimental parameters for CPMG profile tests used to monitor the deposition of two adhesive treatments 


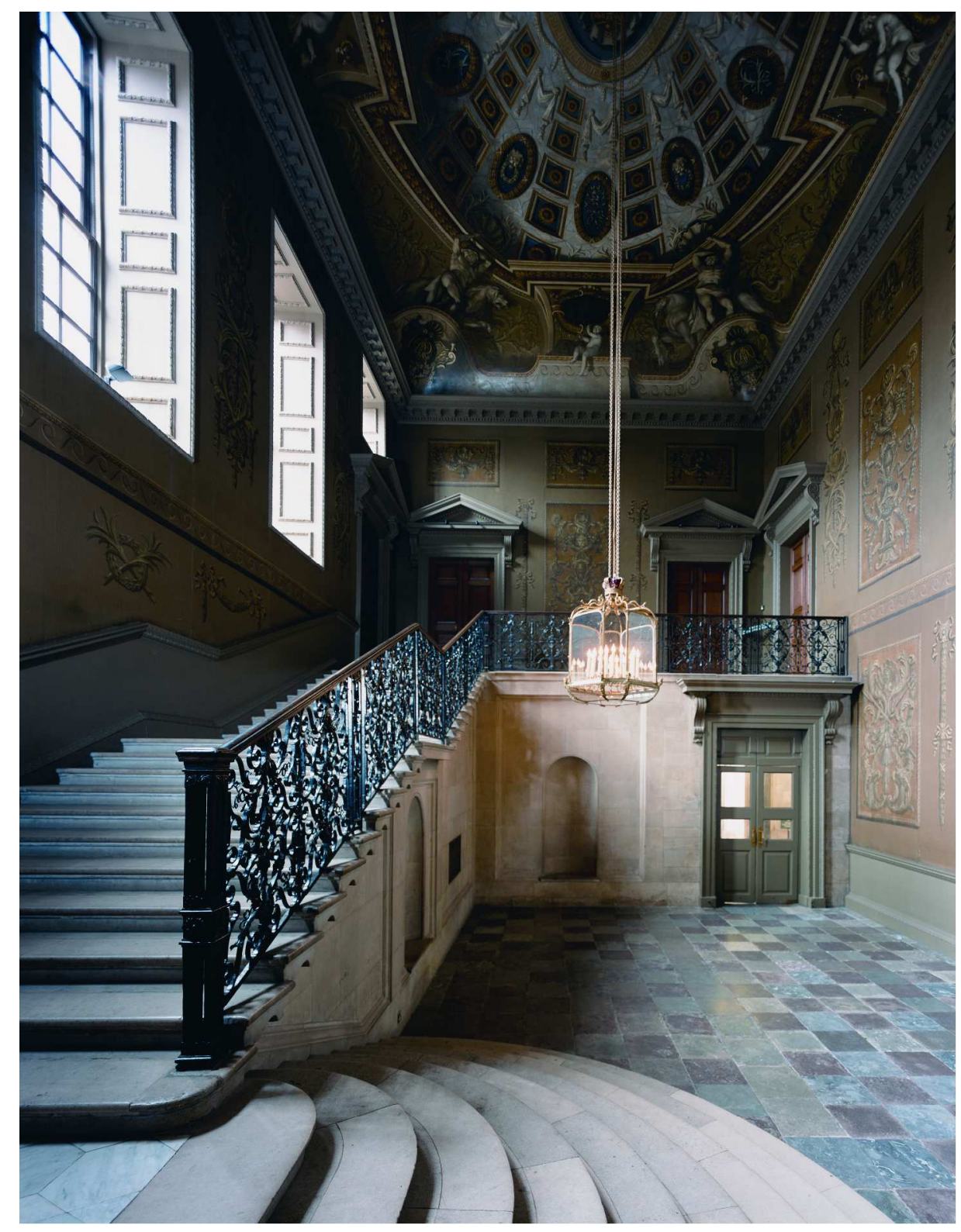

The Queen's Staircase at Hampton Court Palace. (CHistoric Royal Palaces. Photo: Nick Guttridge Figure 1 $458 \times 594 \mathrm{~mm}(300 \times 300$ DPI $)$ 


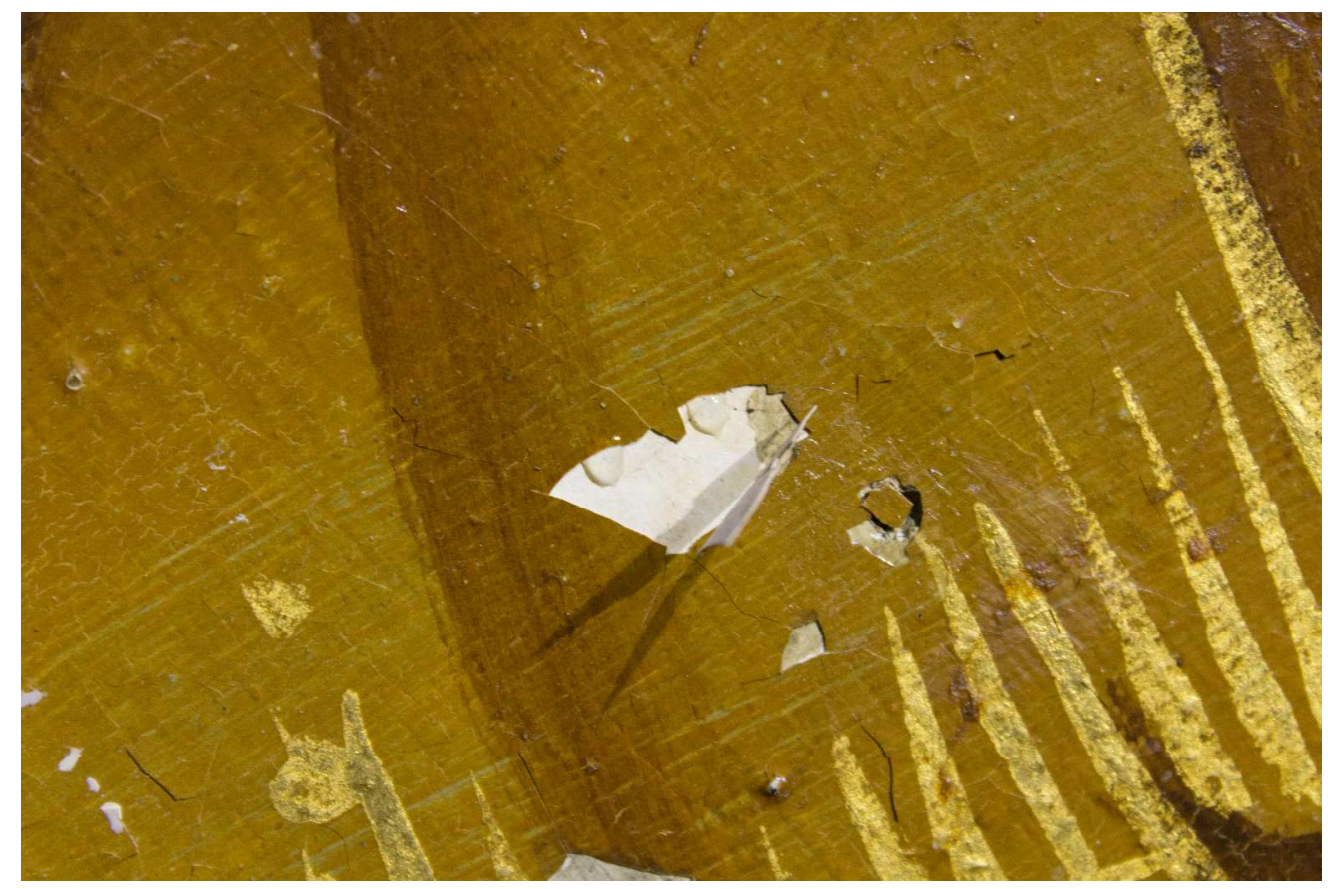

Delamination of paint layers from the plaster substrate and water droplets on hydrophobic BEVA® 371 adhesive from previous treatment

Figure 2

$438 \times 292 \mathrm{~mm}(300 \times 300$ DPI $)$ 


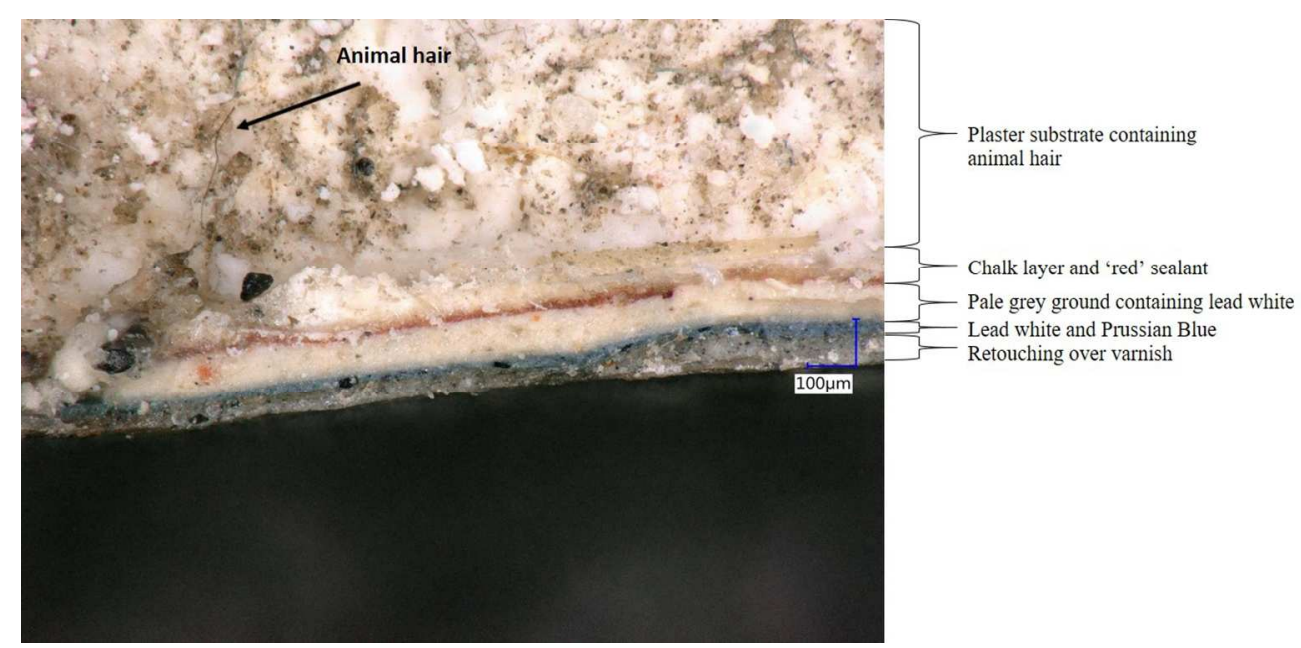

Cross section from William Kent ceiling painting, painted 1734, The Queen's Staircase. Magnification 200x Figure 3

$231 \times 110 \mathrm{~mm}(150 \times 150 \mathrm{DPI})$ 


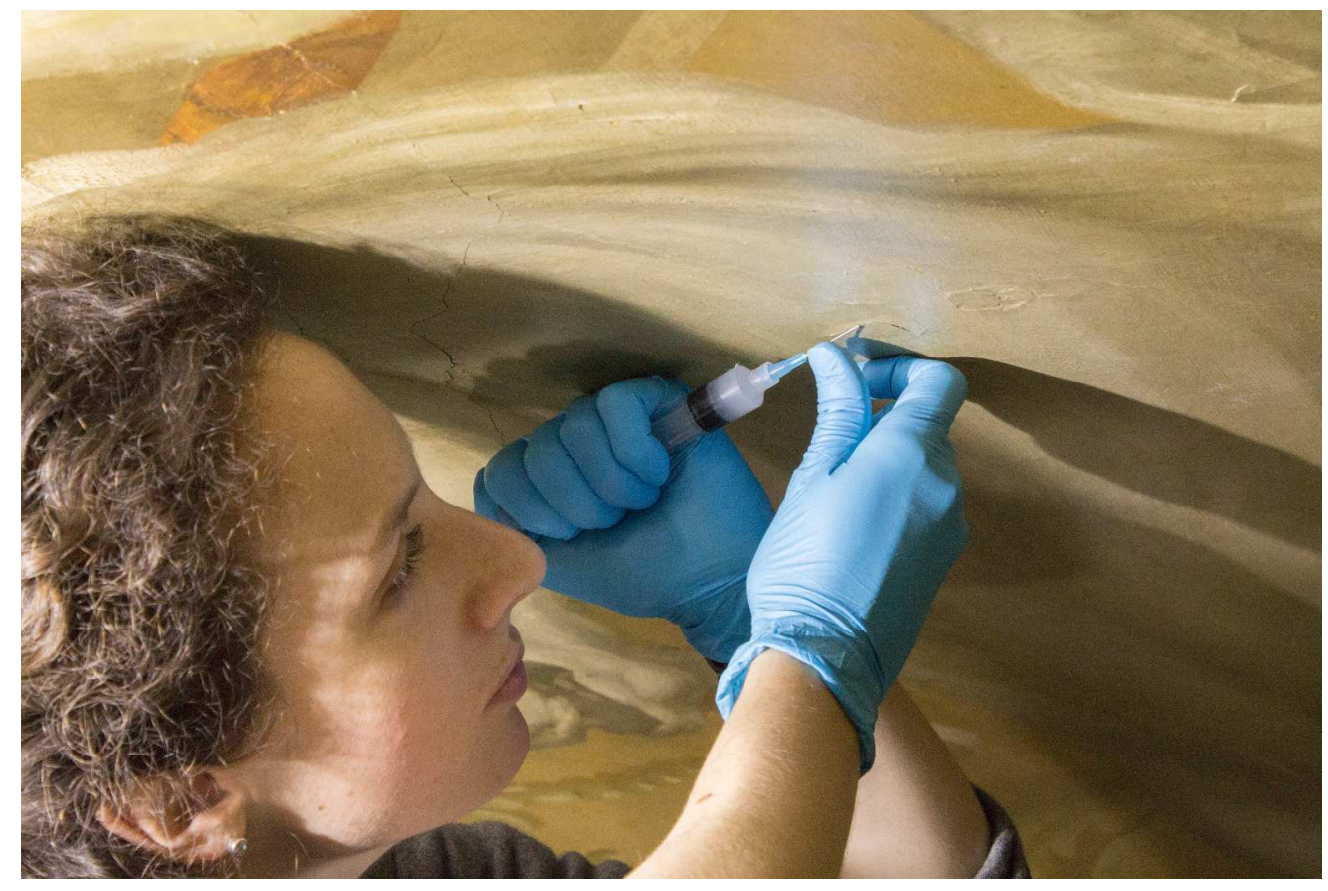

Injection of BEVA $® 371$ adhesive solution behind paint flake Figure 4

$438 \times 292 \mathrm{~mm}(300 \times 300$ DPI $)$ 


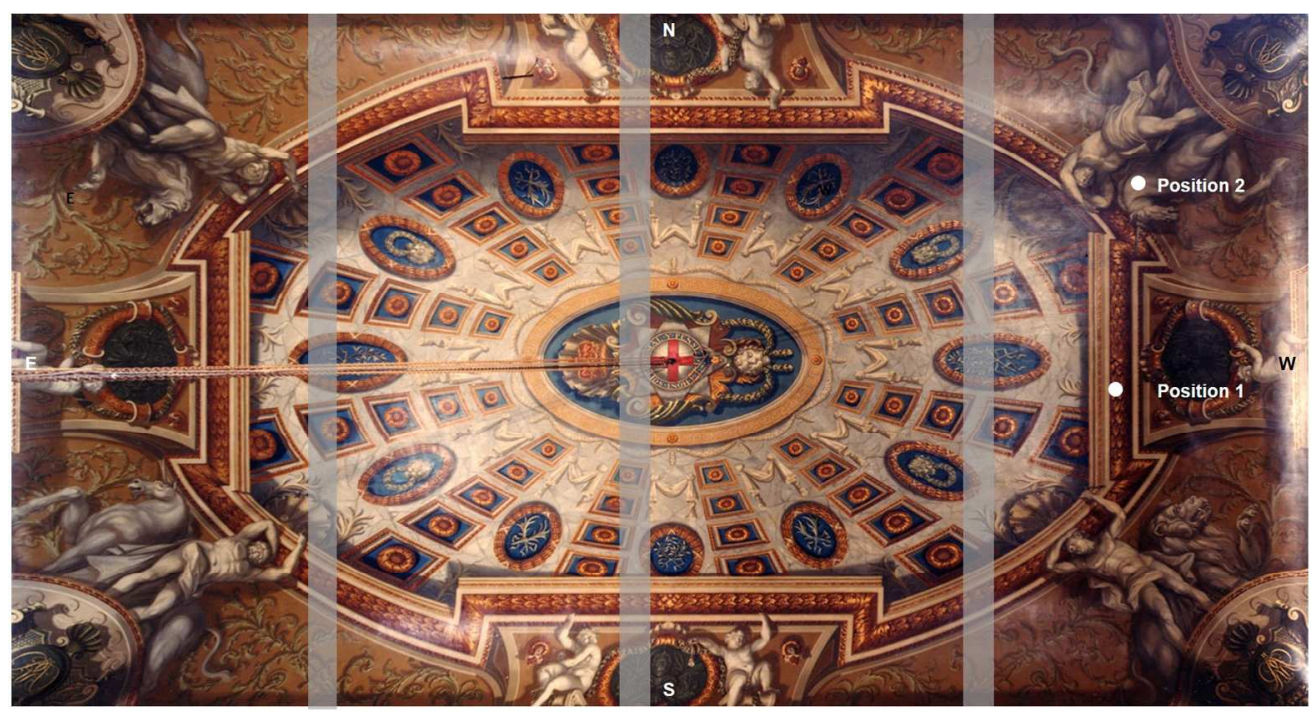

Image of The Queen's Staircase ceiling painting by combined rectified photographs showing locations of NMR analysis and rolled steel joists behind the painting. (CHistoric Royal Palaces

$$
\text { Figure } 5
$$

$301 \times 161 \mathrm{~mm}(150 \times 150 \mathrm{DPI})$ 

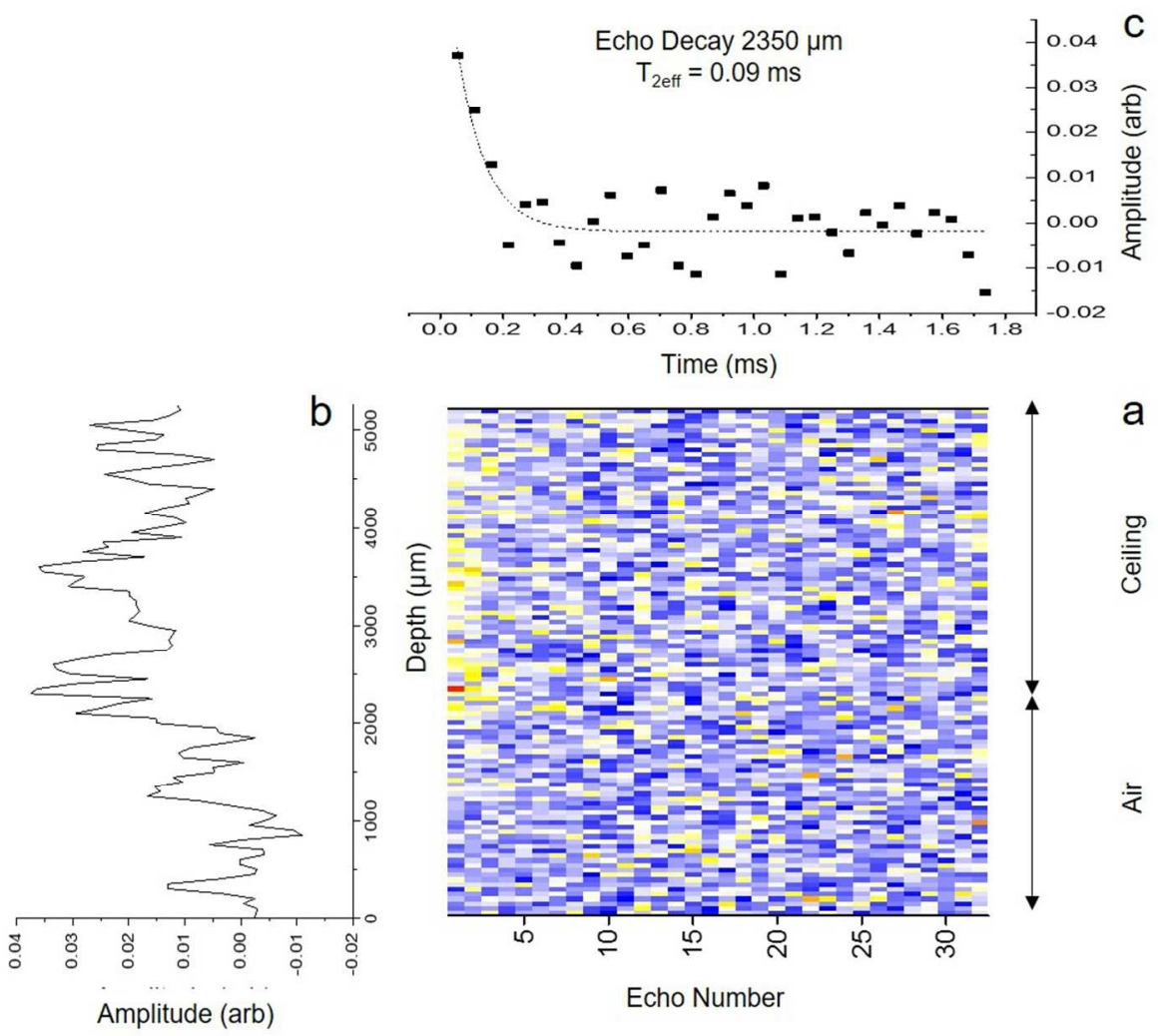

Figure 6 Relaxation data acquired from Position 1 prior to treatment with Jun Funori adhesive (a) 2D contour map showing CPMG echo decays through the depth of the ceiling at $50 \mu \mathrm{m}$ steps, (b) sum echo amplitude of the 1st through 2 nd echoes at each sampling depth at $50 \mu \mathrm{m}$ steps and (c) CPMG echo decay at a depth of $2350 \mu \mathrm{m}$

Figure 6

$194 \times 162 \mathrm{~mm}(150 \times 150 \mathrm{DPI})$ 


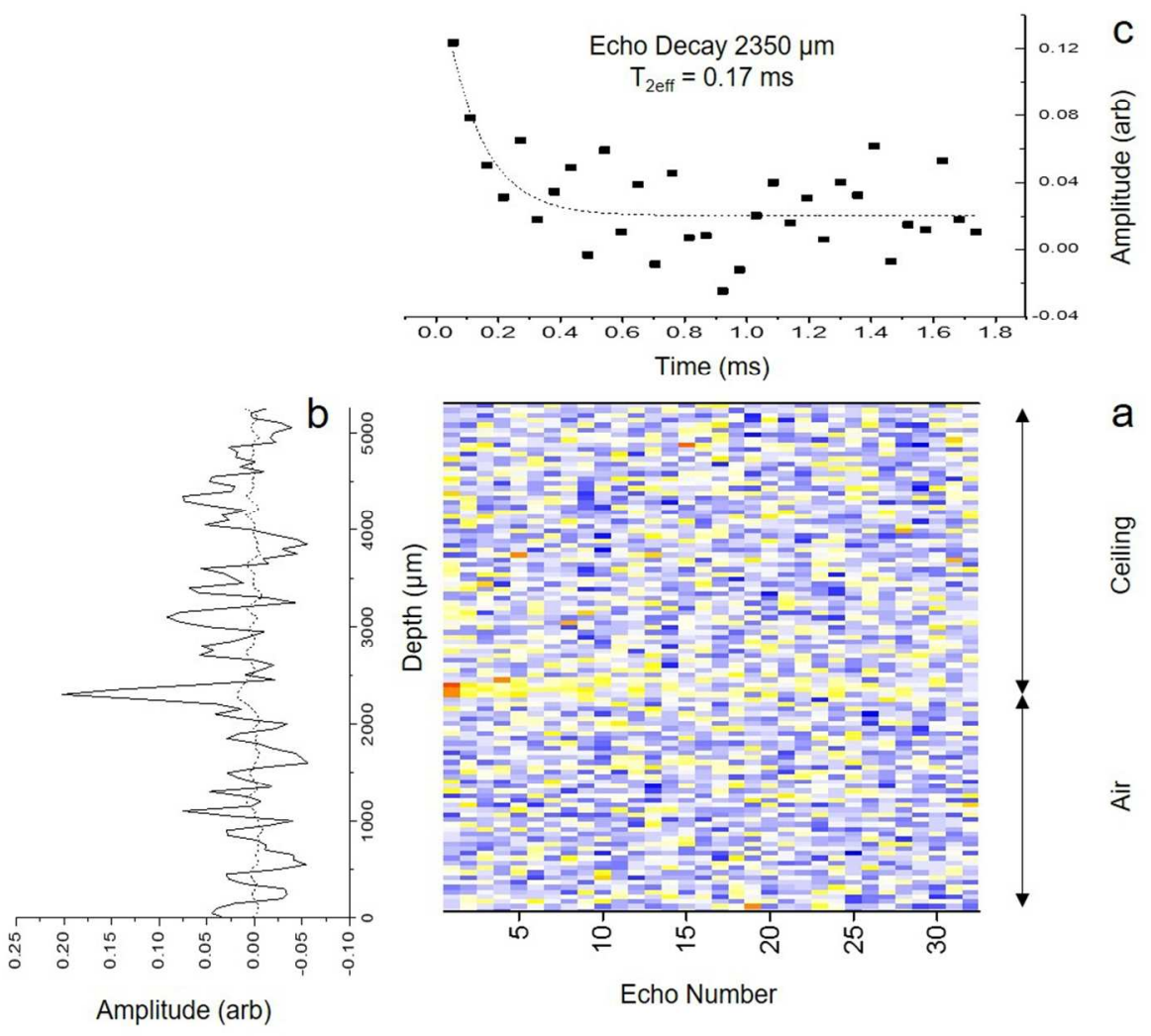

Figure 7 Relaxation data acquired from Position 130 minutes after treatment with Jun Funori adhesive (a) 2D contour map showing CPMG echo decays through the depth of the ceiling at $50 \mu \mathrm{m}$ steps, (b) sum echo amplitude of the 1 st through 2 nd echoes at each sampling depth at $50 \mu \mathrm{m}$ steps and (c) CPMG echo decay at a depth of $2350 \mu \mathrm{m}$

Figure 7

$194 \times 164 \mathrm{~mm}(150 \times 150 \mathrm{DPI})$ 


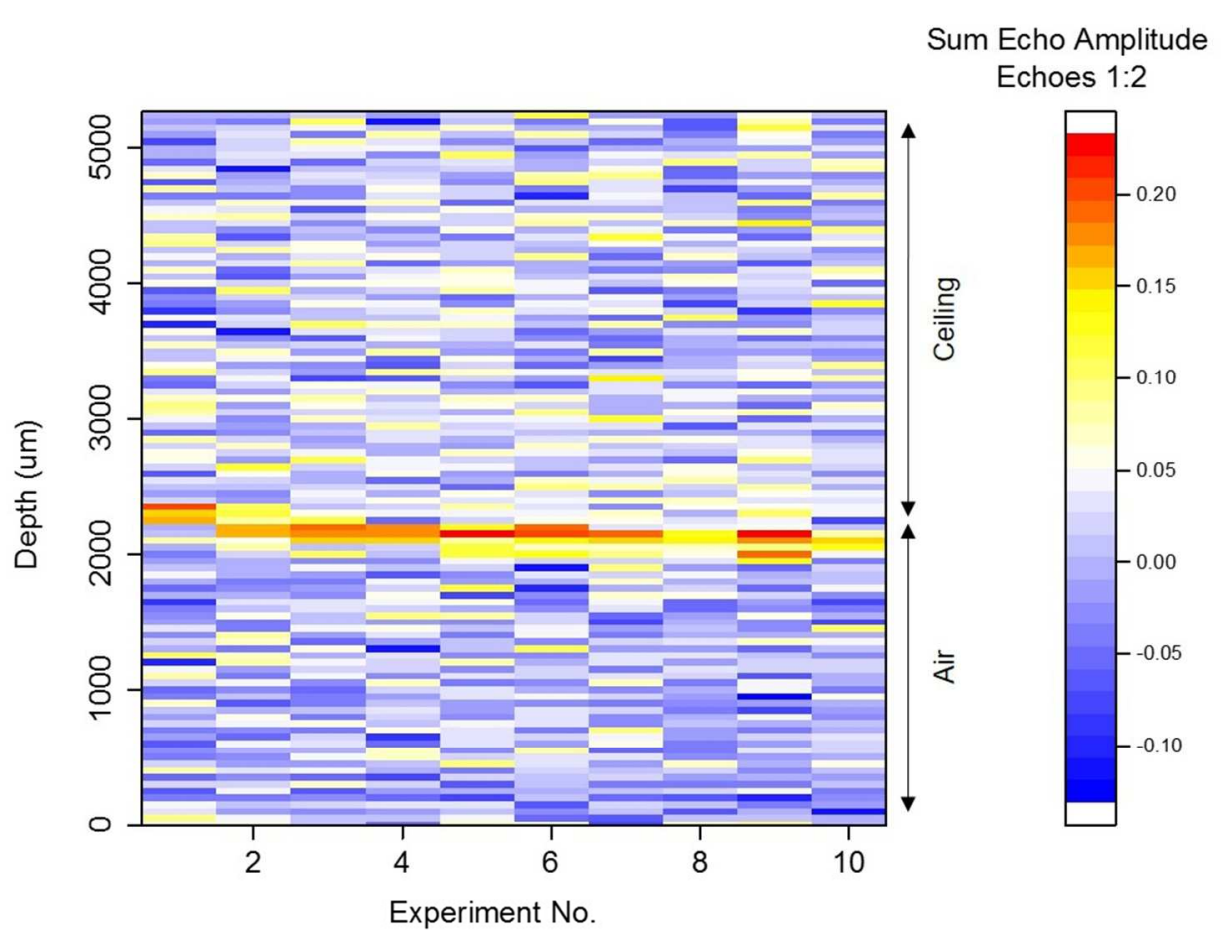

Figure $82 \mathrm{D}$ contour map of the sum echo amplitude for the 1st through 2 nd echoes at each sampling depth over ten consecutive profile scans showing movement of the proton density signal towards the front of the ceiling painting

Figure 8

$184 \times 140 \mathrm{~mm}(150 \times 150 \mathrm{DPI})$ 


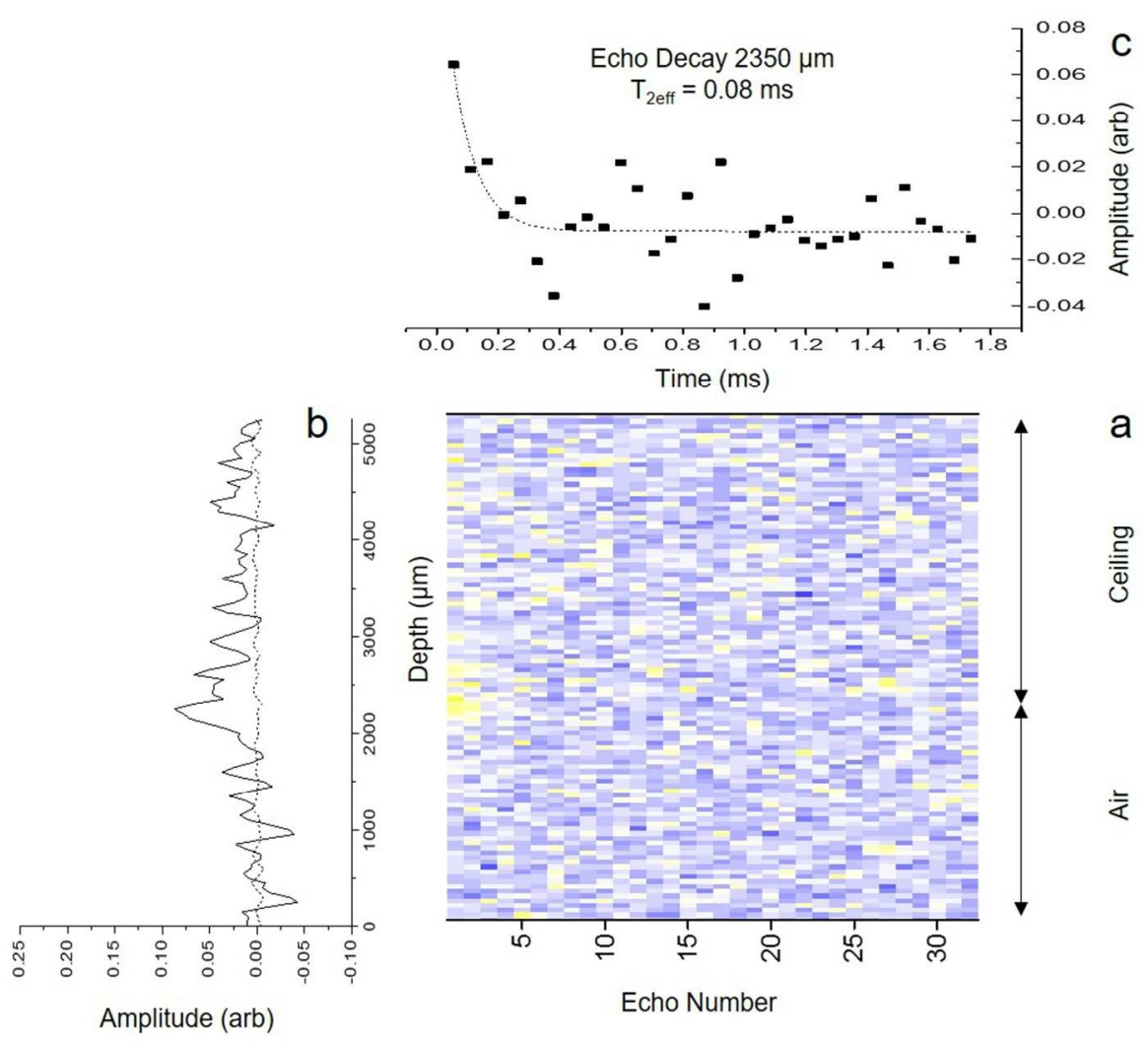

Figure 9 Relaxation data acquired from Position 124 hours after treatment with Jun Funori adhesive (a) 2D contour map showing CPMG echo decays through the depth of the ceiling at $50 \mu \mathrm{m}$ steps, (b) sum echo amplitude of the 1 st through 2 nd echoes at each sampling depth at $50 \mu \mathrm{m}$ steps and (c) CPMG echo decay at a depth of $2350 \mu \mathrm{m}$

Figure 9

$194 \times 164 \mathrm{~mm}(150 \times 150 \mathrm{DPI})$ 


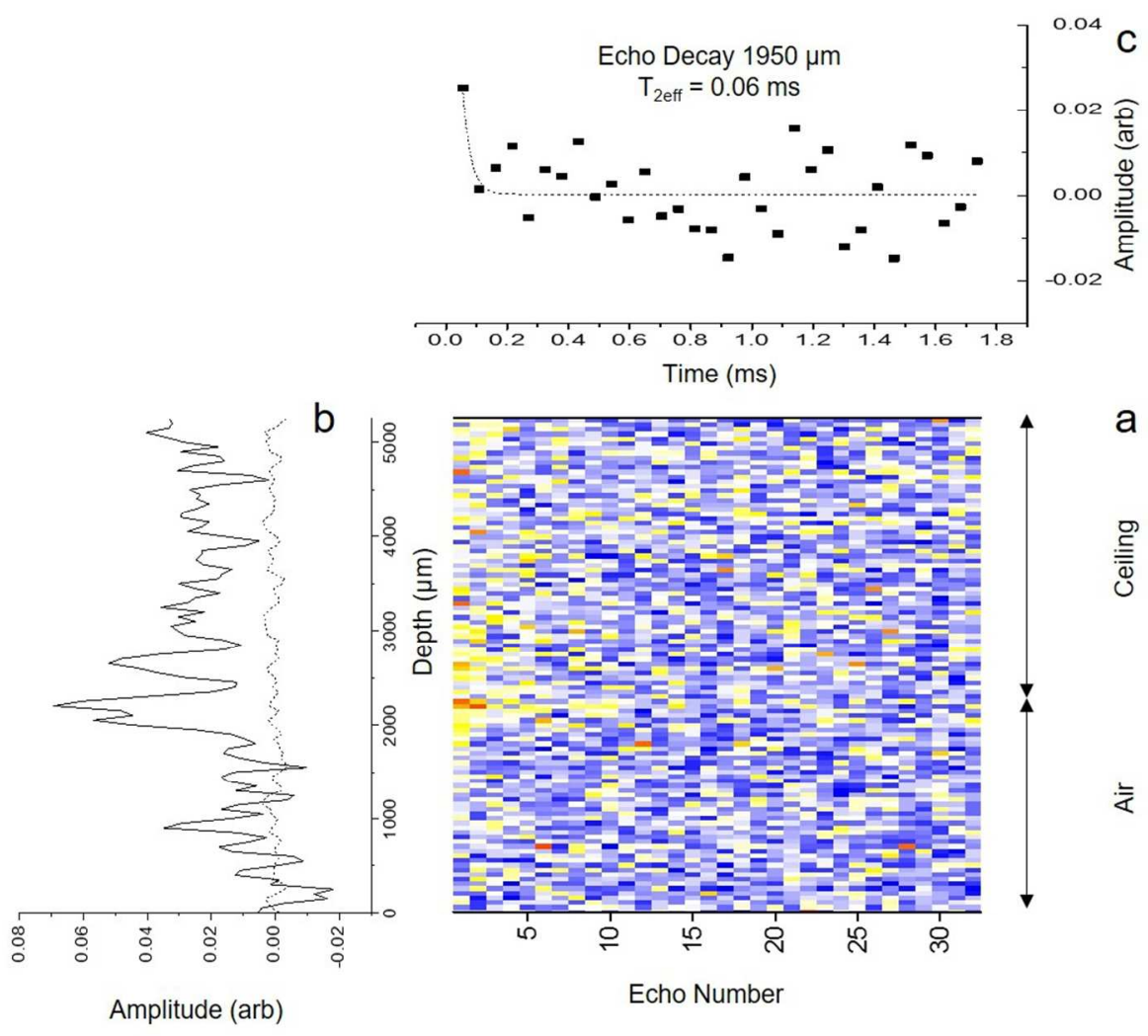

Figure 10 Relaxation data acquired from Position 2 prior to treatment with BEVA® 371 adhesive (a) 2D contour map showing CPMG echo decays through the depth of the ceiling at $50 \mu \mathrm{m}$ steps, (b) sum echo amplitude of the 1st through 2 nd echoes at each sampling depth at $50 \mu \mathrm{m}$ steps and (c) CPMG echo decay at a depth of $1950 \mu \mathrm{m}$

Figure 10

$196 \times 163 \mathrm{~mm}(150 \times 150 \mathrm{DPI})$ 


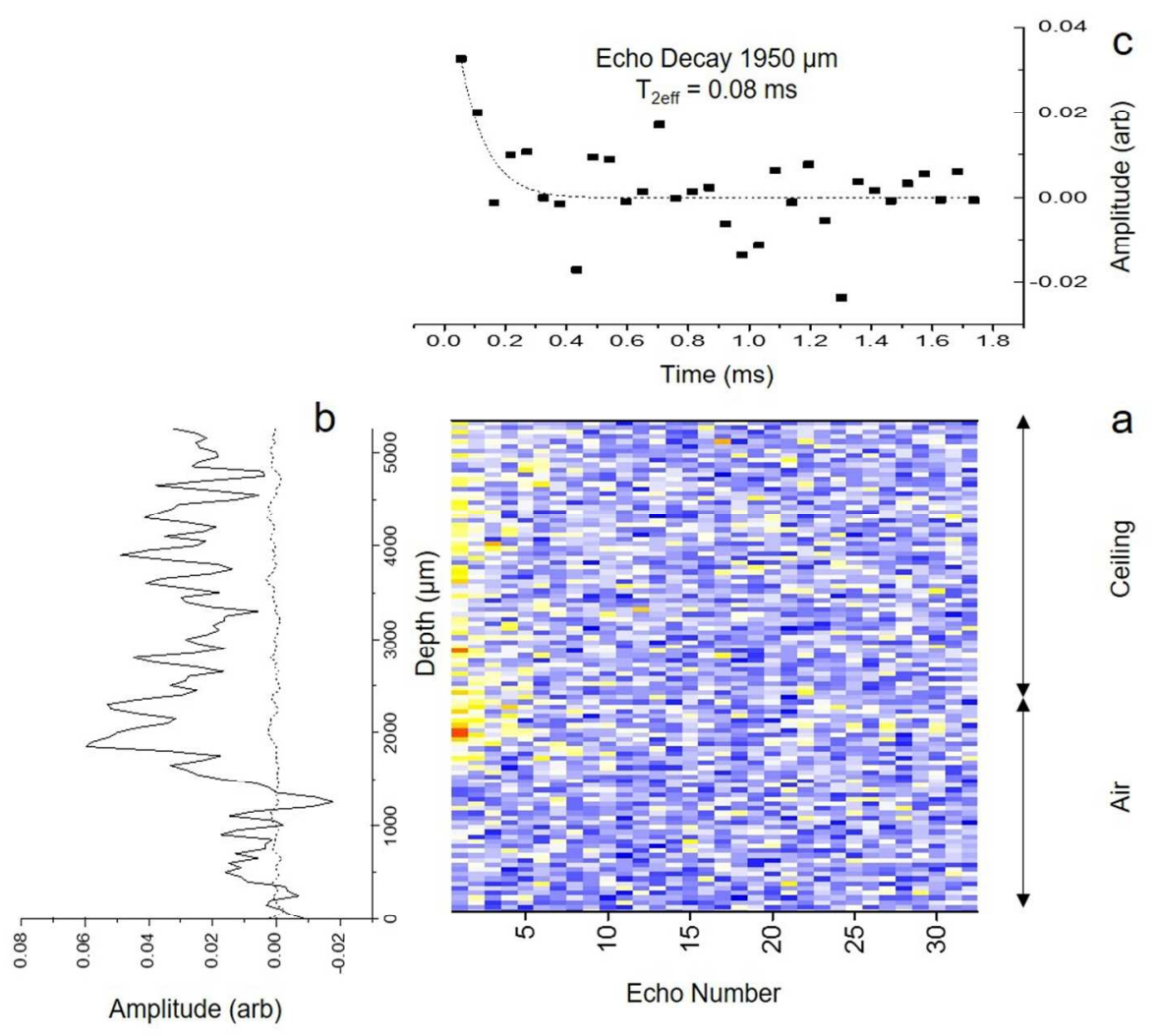

Figure 11 Relaxation data acquired from Position 230 minutes after treatment with BEVA® 371 adhesive (a) 2D contour map showing CPMG echo decays through the depth of the ceiling at $50 \mu \mathrm{m}$ steps, (b) sum echo amplitude of the 1 st through 2 nd echoes at each sampling depth at $50 \mu \mathrm{m}$ steps and (c) CPMG echo decay at a depth of $1950 \mu \mathrm{m}$

Figure 11

$196 \times 164 \mathrm{~mm}(150 \times 150 \mathrm{DPI})$ 